\title{
Mothers' Behaviors and Children's Social Confidence and Ability: Correlations from the NLSY
}

\author{
Kitty To' and Ryan Lange ${ }^{\#}$ \\ ${ }^{1}$ International School, Ho Chi Minh City, Vietnam \\ \#Advisor
}

\section{$\underline{\text { ABSTRACT }}$}

The understanding of shyness and social withdrawal has been built over the past half century with research looking into factors that cause this in children. However, not many mention the natural phenomenon of if children mimic social confidence from their adult figure. This study used correlation analyses to investigate the relations between parents' behaviors and attitudes and their children's social confidence and ability. Data were from the National Longitudinal Survey of Youth, 1986 Child and Young Adult Survey Mother Supplement. Results showed weak correlation between social confidence and outings frequency, either with family and friends or not. However, children who were spanked more frequently positively correlated with their mothers rating them to be more high strung. Furthermore, all hypotheses showed results that follow the direction of the prediction, so further investigation into the topic may show more significant correlation or a causation relationship of the variables.

\section{Introduction}

Shyness is a construct that is defined as an individual's need for avoidance in social interactions, particularly in unfamiliar situations and with unfamiliar people (Cheek and Buss, 1981). Shyness is evident in many people. Although a specific number will never be produced, surveys show between $40 \%$ to $60 \%$ of all adults report themselves as shy in some or all situations (Poole \& Schmidt, 2019).

Early experiments into factors that cause shyness took two approaches: the low-esteem hypothesis, the notion that shyness is caused by a threat of self-esteem to the individual, or the social-skill deficit hypothesis, an understanding that the individual lacks certain social skills, creating difficulties in immersing themselves into social interactions (Crozier, 1982). Although both were viewed as two separate theories, it would seem more valid to consider they may be in fact mutually reinforcing. More recent studies have shown that low self-esteem negatively impacts an individual's social relationships (Harris, 2019) and establishing strong social skills helps maintain good mental health (Sergin, 2017).

\section{Literature Review}

Through the understanding of the two approaches and how they could be mutually reinforcing, it raises the question of what leads to having low esteem or a social skill deficit. Social phobia could develop through childhood or be passed through family members. So what roles do heredity and social conditioning play in the development of these two approaches? Studies into parental or family factors on the development of shyness were conducted through family and twin studies. Monozygotic twins compared to dizygotic twins, of ages ranging from 12 months to 55 years old, show higher mutuality in shyness (Plomin and Daniels, 1986). Zimbardo (1977) proposed that order of birth may play a role in social confidence development. Firstborn or only children tend to be more socially inadequate due to parental expectation (Asendorf, 1986); while younger siblings acquire skills of negotiation earlier because of the power 
disadvantage they have to the older sibling, who would be older and most of the time bigger in size (Zimbardo, 1977). Asendorf (1986) also mentioned that order of birth plays a role in who are most shy, concluding that only children are normally ranked as most shy, followed by first born, middle children, and finally the youngest.

Rubin, Burgess, and Coplan (2014) surveyed factors contributing to a child's social withdrawal. These included biological factors, gender, the child's social interaction with others their age, and parent-child relationship. These included biological factors (Fox \& Calkins, 1993; Levine, 1993), gender (Crozier, 1995), and interactions with peers and parents. Peer interactions with others their age develops a child's understanding of social norms and builds a foundation for learning competent social behavior (Piaget, 1932). Focusing on the parent-child relationship, children who have secure relationships with their parents tend to be more confident in novice situations due to the security they feel with their parents (Kagan et al., 1988). However, a strong relationship is different to overprotective parents, which defeats the purpose of exploring new interactions. Overprotective parents, mothers in particular, tend to limit their child's exploration, leading to them solving problems for the child (Sroufe, 1983). Children with over-controlling mothers tend to have continuous growth in social withdrawal over the developing years and tend not to branch out.

The understanding of mimicry in behavior, focused on children, is a phenomenon that has been highly researched. Patterns of behavior are acquired much faster through watching and learning compared to slow instrumental training in a formal setting (Bandura, 1962). Through naturalistic observations of child's play where frequently the child will reproduce a parent behavior; Things such as mannerisms, voice inflections, and attitudes are normal behavior children pick up from observations and imitations of the parent. Although many children mimic a behavior, they do not reproduce every personality characteristic they see. In observations of behavior, children will identify with the source of the rewarding power rather than the competitor - this meaning that they will, more often than not, only repeat the actions of those who they perceived to have been on the 'good' side (Bandura, 1963). Not only so, but Bandura's (1963) research into nurturing behaviors of the parents help motivate a child to continue or repeat an action they know will have a positive outcome. Through this, the understanding that children mimicking their parent's behavior is normal, which leads to questioning its attributes to establishing a child's social confidence.

Previous research in the field has established the prevalence of shyness and the factors that contribute to it, but has not established a clear relationship concerning a child's mimicry of a parent in showing social withdrawal. This raised the research question "To what extent does a parent's sociability, reservedness, and disciplinary actions affect their child's social confidence and ability?" Sociability in a parent looks into how often they would spend time with other friends and family with the child there. This might show a child basic social skills and help them mimic the behavior around others their age. Reservedness of a parent focuses on how often they spend time outside of the house with them. The understanding that more frequent outings will constitute a child being more socially capable. This strong parent-child relationship is a factor that was discussed above. The final hypothesis looks at how disciplinary actions, in this case spanking, affects a child's social ability - how tense they are. Analyses testing 3 hypotheses were conducted to find correlations between pairs of variables, an activity or act of the mother with the child and a behavior relating to social confidence or ability in the child.

Hypothesis 1 is that the frequency of the family getting together with friends and relatives correlates positively with a child's ability to get along with other children. Hypothesis 2 is that the frequency of outings for a 3 to 5 year old child positively correlates with the child's outgoing nature and desire for interaction with others. Hypothesis 3 is that the number of spanks the child receives weekly will positively correlate with how high strung the child is.

\section{Data and Methods}

Data were taken from the National Longitudinal Survey of Youth (NLSY) from the 1979 Child and Young Adult Cohort, more specifically the Mother Supplement interviews which were conducted in 1986. All questions used as a predictor were taken from the Home Observation for Measurement of Environment (HOME) -Part B for children ages between 3 and 5 and Part $\mathrm{C}$ for all those over 6- assessments. Variables for children were taken from the Behavioural Problem Index questions for children of all ages. In these sections of the survey, mothers responded to questions about 
their family activities, their parenting styles, and various characteristics of their children. Responses to these questions were given in Likert scale format (indicating level of agreement or disagreement), binned frequency, or raw frequency. Six variables, each derived from one survey question, were picked to test the three hypotheses from the Introduction. All participants interviewed were current residents of the United States, with the following demographic breakdown: Non-Black/Non-Hispanic (63\%); Black Non-Hispanic (28\%); Hispanic or Latino (16\%). Children of these mothers were between the ages of 0 and 23 at the time of the 1986 interviews. Also, not all mothers answered every question (either depending on the age of the child or the question was never answered), and some mothers answered questions for multiple children. For each of the analyses correlating two question responses, I restricted observations to include only children whose mothers had given valid responses to both questions.

\section{Hypothesis 1: Frequency of get-togethers predicts child's child's social adjustment}

To test Hypothesis 1, which predicts that the frequency of the family getting together with friends and relatives (operationalized through a mothers rating of the families frequent get together) correlates positively with the child's ability to get along with other children (operationalized through the mothers rating of the child's social adjustment), I tested the correlation between responses to survey items C0545700 (GET_TOGETHERS) and C0565100 (GETS_ALONG_OTHER_CHILDREN). When the levels of the predictor and outcome variables were cross-tabulated, numerous cells had fewer than 30 observations; this would have made an ordinal logistic regression analysis under-powered. To get sufficient data for each cross-tabulated cell, the levels of the two variables were collapsed to binary which is presented in Table 1 . I predict that an increase in family get-togethers will positively correlate the child's social confidence. This is because the child is introduced to seeing their mothers interacting with other friends and family; building that understanding of social interactions and mimicking the behavior with others their age.

Table 1. Original and binary scales of responses for Hypothesis 1.

\begin{tabular}{|c|c|c|c|c|c|}
\hline \multicolumn{3}{|c|}{$\begin{array}{l}\text { How often the family gets together with } \\
\text { friends or relatives }\end{array}$} & \multicolumn{3}{|c|}{$\begin{array}{l}\text { The child has trouble getting along with other } \\
\text { children }\end{array}$} \\
\hline \multicolumn{2}{|c|}{ Original scale } & \multirow{3}{*}{$\begin{array}{l}\text { Binary scale } \\
\text { (Once per } \\
\text { month or less) }\end{array}$} & \multicolumn{2}{|c|}{ Original scale } & \multirow{3}{*}{$\begin{array}{l}\text { Binary scale } \\
0 \\
0 \\
\text { (Ever true) }\end{array}$} \\
\hline 1 & $\begin{array}{l}\text { Once a year or } \\
\text { less }\end{array}$ & & 1 & Often True & \\
\hline 2 & $\begin{array}{l}\text { About once a } \\
\text { month }\end{array}$ & & 2 & Sometimes True & \\
\hline 3 & $\begin{array}{l}2-3 \text { times a } \\
\text { month }\end{array}$ & \multirow{3}{*}{$\begin{array}{l}1 \\
\text { (Twice per } \\
\text { month or more) }\end{array}$} & 3 & Not True & $\begin{array}{l}1 \\
\text { (Never true) }\end{array}$ \\
\hline 4 & $\begin{array}{l}\text { Several times a } \\
\text { week }\end{array}$ & & & & \\
\hline 5 & $\begin{array}{l}\text { Once a day or } \\
\text { more }\end{array}$ & & & & \\
\hline
\end{tabular}

Hypothesis 2: Frequency of outings predicts whether child is withdrawn 
Hypothesis 2, which predicts frequency of outings of a 3-5 year old (operationalized through a mother's rating of how often the child is brought on a trip) will positively correlate to the child's outgoing nature (operationalized through a mother's rating of how withdrawn the child is). Correlation was tested between responses to survey items C0543700 (OUTINGS_FREQUENCY) and C0566000 (WITHDRAWN). Similar to Hypothesis 1, downsampling of both survey questions into binary variables was necessary for analysis. Binomial logistic regression will also be used for correlation analysis for this hypothesis. I predict that an increase in outings a child has will negatively correlate to how withdrawn the child is. See Table 2 for the original and binary scales for the two variables used to test Hypothesis 1.

Table 2. Original and binary scales of responses for Hypothesis 2.

\begin{tabular}{|c|c|c|c|c|c|}
\hline \multicolumn{3}{|c|}{ How often the child is taken on an outing } & \multicolumn{3}{|c|}{$\begin{array}{l}\text { The child is withdrawn, does not get involved } \\
\text { with others }\end{array}$} \\
\hline \multicolumn{2}{|c|}{ Original scale } & Binary scale & \multicolumn{2}{|c|}{ Original scale } & Binary scale \\
\hline 1 & $\begin{array}{l}\text { Once a year or } \\
\text { less }\end{array}$ & \multirow{2}{*}{$\begin{array}{l}0 \\
\text { (Once per } \\
\text { month or less) }\end{array}$} & 1 & Often True & \multirow{2}{*}{$\begin{array}{l}0 \\
\text { (Ever true) }\end{array}$} \\
\hline 2 & $\begin{array}{l}\text { About once a } \\
\text { month }\end{array}$ & & 2 & Sometimes True & \\
\hline 3 & $\begin{array}{l}2-3 \text { times a } \\
\text { month }\end{array}$ & \multirow{3}{*}{$\begin{array}{l}1 \\
\text { (Twice per } \\
\text { month or more) }\end{array}$} & 3 & Not True & $\begin{array}{l}1 \\
\text { (Never true) }\end{array}$ \\
\hline 4 & $\begin{array}{l}\text { Several times a } \\
\text { week }\end{array}$ & & & & \\
\hline 5 & $\begin{array}{l}\text { Once a day or } \\
\text { more }\end{array}$ & & & & \\
\hline
\end{tabular}

\section{Hypothesis 3: Frequency of spanks predicts how high-strung child is}

Hypothesis 3 examines the prediction of how often a child is spanked by the mother (operationalized through a mother's estimate to how many times they spanked their child in the past week) will positively correlate to how high strung the child is (operationalized through a mother's rating of their child's social ability). Responses to survey items C0547100 (SPANKS_FROM_MOTHER) and C0564200 (HIGH_STRUNG) were tested to find correlation. Similar to the other two hypotheses' outcome variables, HIGH_STRUNG was measured on a 1-3 scale, where 1 was “Often true," 2 was "Sometimes true," and 3 was "Not true." However, unlike the other two hypotheses' predictor variables, the number of spanks was not given on any scale, but was rather an approximate number of spanks the child received from the mother in the past week. Thus, Spearman rank-order correlation will be used for this correlation analysis.

All data analyses were performed with the SAS/STAT® statistical analysis software, version 3.8 (SAS Institute, 2021). On SAS, valid responses of the predictor and response were filtered to avoid missing values when performing the correlation analysis.

\section{Results}




\section{Hypothesis 1}

The Maximum Likelihood Estimate (MLE) technique was used to estimate the parameters of the model through calculations of conditional probability, the likelihood of one event occurring given another. The table of results for this hypothesis shows the degrees of freedom, slope estimate (which determines how weak or strong and in which direction the correlation is going in), Wald chi-square statistic, and the p-value ( $\mathrm{Pr}>\mathrm{ChiSq}$ ) which are test statistics calculated.

Table 3 shows model estimates and probability for the binomial logistic regression model predicting variation in variable GETS_ALONG_OTHER_CHILDREN from variation in variable GET_TOGETHERS. The estimated figure shows a weak negative correlation between the two variables, which although means that the data is in the direction of prediction - children who go on more family get-togethers tend to get along with other children better, but the effect is small and not statistically significant $\left(\chi^{2}=1.0704 ; p=0.3009\right)$.

Table 3. Binomial logistic regression model for Hypothesis 1.

\begin{tabular}{|l|l|l|l|l|l|l|}
\hline \multicolumn{2}{|l|}{ Analysis of Maximum Likelihood Estimates } \\
\hline Parameter & & DF & Estimate & Standard Error & Wald Chi-Square & p-value \\
\hline Intercept & & 1 & 1.0522 & 0.0612 & 295.4027 & $<0.0001$ \\
\hline GET_TOGETHERS & 0 & 1 & -0.2219 & 0.2144 & 1.0704 & 0.3009 \\
\hline
\end{tabular}

\section{Hypothesis 2}

The same binomial logistic regression analysis was used for the second hypothesis predicting the variable WITHDRAWN by OUTINGS_FREQUENCY. The estimated value shows a weak negative correlation between the two variables; so although the direction of the prediction aligns with the prediction of increase in outings for a child will show a not-withdrawn child, the correlation is not strong to show any significance $\left(\chi^{2}=3.5927 ; p=0.0580\right)$. See Table 4 for the model relating WITHDRAWN to OUTINGS_FREQUENCY.

Table 4. Binomial logistic regression model for Hypothesis 1.

\begin{tabular}{|l|l|l|l|l|l|l|}
\hline \multicolumn{2}{|l|}{ Analysis of Maximum Likelihood Estimates } \\
\hline Parameter & & DF & Estimate & Standard Error & Wald Chi-Square & p-value \\
\hline Intercept & & 1 & 1.8599 & 0.1020 & 322.2676 & $<0.0001$ \\
\hline $\begin{array}{l}\text { OUTINGS_FRE- } \\
\text { QUENCY }\end{array}$ & 0 & 1 & -0.3844 & 0.2028 & 3.5927 & 0.0580 \\
\hline
\end{tabular}

\section{Hypothesis 3}

Contrasting to the other 2 hypotheses, all values were kept for Hypothesis 3, which predicts number of spanks from mother will positively correlate to how high strung the child will be. Therefore, distribution of number of spanks was studied at all three levels of high strung of a child is. 
Observations of the figure below show most parents spank their child twice a week. The mean value is presented on each graph which shows that as HIGH_STRUNG levels increase, the mean value of spanks decreasesmeaning that as mothers rate their children not high-strung, the mean number of times they spanked their child also decreased. See Fig. 1 for distribution of number of spanks at each level of HIGH_STRUNG.

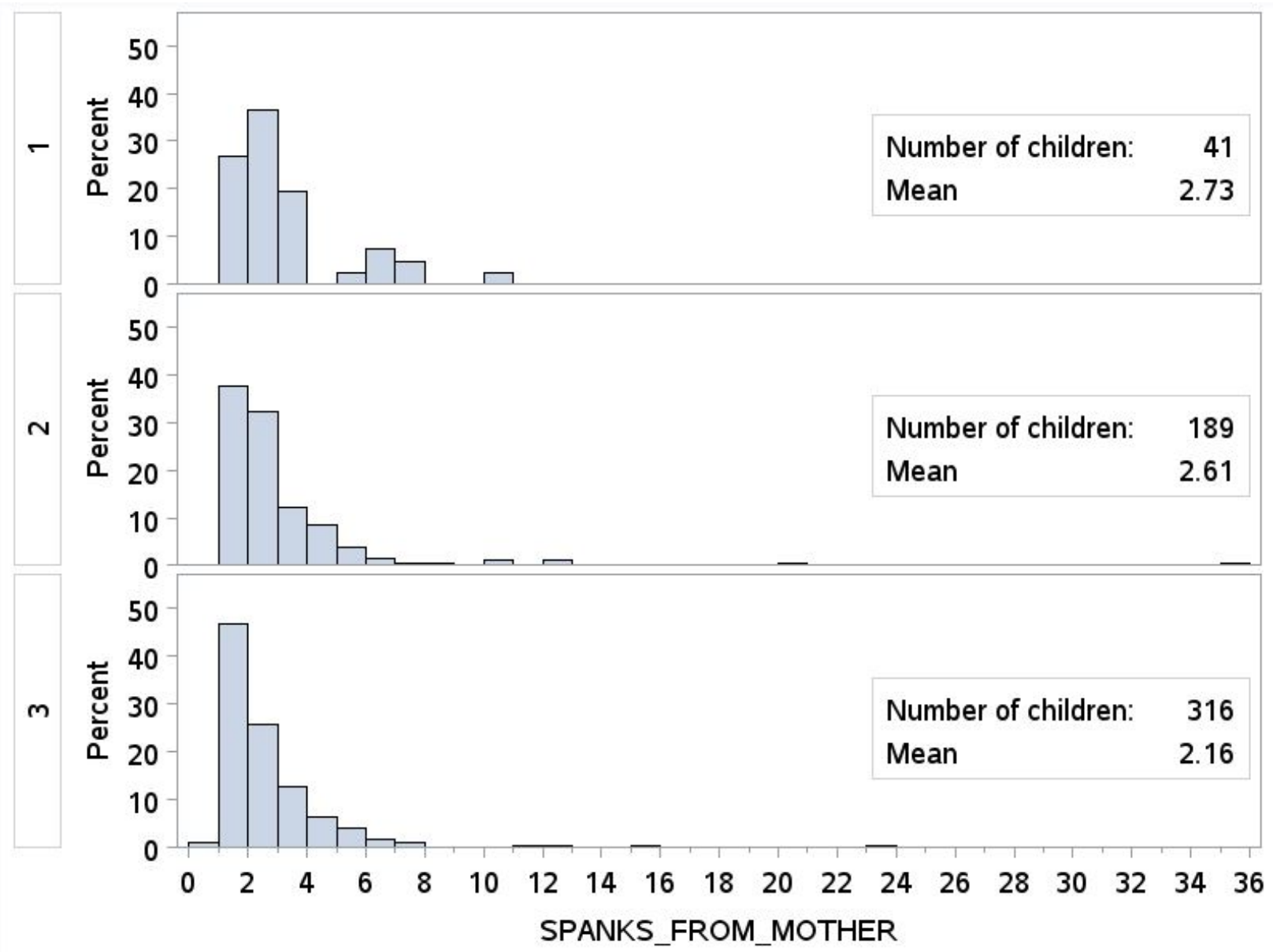

Figure 1. Distribution of number of spanks at each level of HIGH_STRUNG.

The Spearman rank-order correlation analysis confirmed the pattern of results seen in the histograms, showing a negative correlation between number of spanks and ratings of HIGH_STRUNG $(\rho=-0.12031 ; p=0.0049)$. Since the levels of HIGH_STRUNG were 1=often high-strung, $2=$ sometimes high-strung, and $3=$ never high-strung, this meant that being spanked more frequently correlates with being more high strung. The p-value of $<0.01$ shows strong evidence against the null hypothesis—-meaning the null hypothesis is rejected.

Table 5. Spearman rank-order correlation analysis for Hypothesis 3.

\begin{tabular}{|c|c|c|}
\hline \multicolumn{3}{|c|}{$\begin{array}{l}\text { Spearman Correlation Coefficients, } N=546 \\
\text { Prob }>|r| \text { under H0: } \rho=0\end{array}$} \\
\hline & HIGH_STRUNG & SPANKS_FROM_MOTHER \\
\hline
\end{tabular}




\begin{tabular}{|l|l|l|}
\hline & 1.0000 & -0.1203 \\
HIGH_STRUNG & - & 0.0049 \\
\hline
\end{tabular}

\section{Discussion and Limitations}

Hypothesis 1 which examines a parent's sociability and reservedness in the context with other friends and relative members. Results showed that increased frequency of get togethers did not correlate to children having an easier time socializing with others their age. Another study to look into a parent's social network and its effect on children between the age of 9 and 11 showed different results. A parent social network was divided into 2 separate categories; a) dependable friends (who they call for an emergency), and b) those who they know in a formal capacity (work events, colleagues, bosses/employees...). Both groups of candidates in the study showed to influence the child's growth in their social skills, happiness, dealing with negative emotions, and change in school the most and results concluded that these networks of friends helped the child understand these necessary skills of communicating and socializing (Homel et. al., 1987). Although their results were different, it is necessary to understand that their experiments were looking for a specific causal relationship between the variables. The present study's data were taken from a database of hundreds of questions asked to the mother specifically. Therefore, these results may not reflect the accurate interpretations of the child's social confidence. Further testing of how the data has changed over the past 50 years and looking at a way to measure the child's ability to get together with others their age in a different way - not through a mother's rating - might show results that align with Homel et al. (1987) better.

Hypothesis 2 examined the frequency of outings and how withdrawn the child is. Results showed that although the correlation was in the direction of prediction, it was not statistically significant. This being said, there are many studies that have looked into this particular problem of a parent-child relationship and its effect on how withdrawn a child is (East, 1991). Studies into reserved and withdrawn parents - focusing on divorced parent relationships - showed that this negatively impacts their child's adjustment in school and at home (Wood et, al. 2004). Although this study focuses on other factors that may be seen as parental withdrawal, the connection could be made to show that children of divorced parents or parents that are fighting are not getting the attention that they need and lose the emotional security they once had to build that was needed to build social security (Anderson, 2014). Not only so, Anderson also noticed a trend of college students - whose parents are separated - continue to struggle with aftermath anxiety and depression that was caused by the divorce. A list of other social problems also might occur such as emotional distress and decrease in social maturity. Similarly, the parents also show signs of social withdrawal and separate themselves from their old community. So although the results in this paper showed that there is no strong correlation between the 2 variables, more research into the relationship might show there is a mimicking of withdrawal from parent to child.

Unlike Hypotheses 1 and 2, Hypothesis 3 showed that spanking positively correlates to a more high strung and tense child. Although the study does show a correlation between the number of spanks and how high strung a child is, this only shows a correlation, not a causation. Therefore, for any evidence to show that spankings will cause a child to be more high strung, further investigation and experiments will need to be conducted. However, spanking is a controversial child rearing practice that has negative impacts on the child's mental health and has been shown to be ineffective in disciplining a child. Gershoff (2013) explained that acts of physical punishment are linked to aggression, delinquent behavior in childhood, strain on the parent/child relationship, and criminal behavior. The most concerning repercussions of spankings are the physical abuse links that children make. Many documented cases of physical abuse are of children misperceiving a physical punishment from a parent (Durrant et al., 2006). Other studies also 
have noticed that spankings can lead to poor personal adjustment (depression) or poor social adjustment (social withdrawal) (Alibrando, 1988). Linking this back to the hypothesis, the studies show that spanking, although ineffective in disciplining a child, does cause a lot of other behavioral issues, one of which would show connections to the findings in this paper.

There are also other limitations to this study through data collection. The dataset's respondents were all mothers from the United States, so cultural differences might show a different correlation between the variables suggested. Not only that but the data set was taken from 1986; therefore, the data taken might not be the most up-to-date. All variables used in this study were ratings from the mother based on activity and behavior around the child. This is subjective to the mothers views on their child, therefore, biases might show results that are not true in survey answers. Not only so but questions were directed at the mothers exclusively. E.g. The number of spanks a child received was only asked for how many the mother gave in the past week. Other guardians figures were not included in this number, therefore, the number of reported spanks the child received may be lower than what they did get. Additionally, because the results only show correlation and not causation, no solid conclusions were made. Extraneous variables might interfere with results and it would not be possible to identify which ones and why.

Through all this research and data analysis, the research question that was asked can be answered with the variables that were used. Although the data analysis showed that social confidence is not heavily influenced by outings frequency - either with family or friends or not - and spankings do affect how high strung a child is, past literature helped further understand the cause for the results. For future research on the topic, it is necessary to consider all these limitations and create experiments that may support the ideas in this paper.

\section{Acknowledgments}

Thank you to Ryan for being such a great help throughout the entire project. Each week helping me with anything I had trouble with and made sure I understood the tasks. I don't think I would have been able to finish any of this without your constant support. Special thanks to Lumiere for being a great project and allowing me the opportunity create this paper. The entire team was very helpful throughout the time and was very ready to answer any questions that I had so thank you to you all for the experience I had.

\section{References}

Anderson J. (2014). The impact of family structure on the health of children: Effects of divorce. The Linacre quarterly, 81(4), 378-387. https://doi.org/10.1179/0024363914Z.00000000087.

Alibrando, S.A. (1988). The effects of corporal punishment and contextual parental characteristics on rebelliousness, neuroticism and introversion. Biola University. ProQuest Dissertations Publishing.

Asendorpf, J. (1986). Shyness in middle and late childhood. In W. H. Jones, J, M. Cheek, \& S. R. Briggs (Eds.), Shyness: Perspective on research and treatment (pp. 91-103). New York: Plenum. https://doi.org/10.1007/978-14899-0525-3.

Bandura, A. (1962) Social learning through imitation. In M. R. Jones (ED.), Nebraska Symposium on Motivation. Lincoln: Univer. Nebraska Press. Pp. 211-269. https://doi.org/10.1007/978-1-4419-1428-6 1257.

Bandura, A., \& McDonald, F. J. (1963) The influence of social reinforcement and the behavior of models in shaping children's moral judgments. J. Abnorm. Soc. Psychol., 67(3), 274-281. https://doi.org/10.1037/h0044714. 
Bureau of Labor Statistics, U.S. Department of Labor. National Longitudinal Survey of Youth 1979 cohort, 19792016 (rounds 1-27). Produced and distributed by the Center for Human Resource Research (CHRR), The Ohio State University. Columbus, OH: 2019.

Cheek, J. M., \& Buss, A. H. (1981). Shyness and sociability. Journal of Personality and Social Psychology, 41(2), 330-339. https://doi.org/10.1037/0022-3514.41.2.330

Crozier, W.R. Explanations of social shyness. (1982). Current Psychological Reviews 2, 47-59. https://doi.org/10.1007/BF02684454.

Crozier, W. R. (1995). Shyness and self-esteem in middle childhood. British Journal of Educational Psychology, 65, 85-95. https://doi.org/10.1111/j.2044-8279.1995.tb01133.x.

Durrant J, Trocmé N, Fallon B, Milne C, Black T, Knoke D. CECW Information Sheet \#41E. University of Toronto, Faculty of Social Work; Toronto, ON: 2006. Punitive violence against children in Canada.

East, P. (1991). The Parent-Child Relationships of Withdrawn, Aggressive, and Sociable Children: Child and Parent Perspectives. Merrill-Palmer Quarterly, 37(3), 425-443. Retrieved September 2, 2021, from http://www.jstor.org/stable/23087398

Fox, N. A., \& Calkins, S. D. (1993). Pathways to aggression and social withdrawal: Interactions among temperament, attachment, and regulation. In K. Rubin \& J. Asendorpf (Eds.), Social withdrawal, inhibition, and shyness in childhood. Hillsdale, NJ: Erlbaum.

Gershoff E. T. (2013). Spanking and Child Development: We Know Enough Now To Stop Hitting Our Children. Child Development Perspectives, 7(3), 133-137. https://doi.org/10.1111/cdep.12038.

Harris, M. A., \& Orth, U. (2019). The Link Between Self-Esteem and Social Relationships: A Meta-Analysis of Longitudinal Studies. Journal of Personality and Social Psychology. http://dx.doi.org/10.1037/pspp0000265.

Homel R, Burns A, Goodnow J. (1987) Parental Social Networks and Child Development. Journal of Social and Personal Relationships. 1987;4(2):159-177. https://doi.org/10.1177/0265407587042004

Kagan J., Reznick, J. S., \& Snidman, N. (1988). Biological basis of childhood shyness. Science, 240, 167-171. https://doi.org/10.1126/science.3353713.

Levine, S. (1993). The influence of social factors on the response to stress. Psychotherapy and Psychosomatics, 60, 33-38. https://doi.org/10.1159/000288677.

Piaget, J. (1932). The moral judgment of the child. Glencoe, IL: Free Press. https://doi.org/10.1007/978-0-38779061-9 2167.

Poole, K. L., \& Schmidt, L. A. (2019). Smiling through the shyness: The adaptive function of positive affect in shy children. Emotion, 19(1), 160-170. https://doi.org/10.1037/emo0000426 
Putallaz, M., \& Heflin, A. (1990). Parent-child interaction. In S. Asher \& J. Coie (Eds.), Peer rejection in childhood (pp. 189-216). New York: Cambridge University Press.

SAS Institute Inc. (2013). SAS/ACCESS® 9.4 Interface to ADABAS: Reference. Cary, NC: SAS Institute Inc.

Segrin, Chris. (2017). Indirect Effects of Social Skills on Health Through Stress and Loneliness. Health Communication. 1 DOI: 10.1080/10410236.2017.1384434

Sroufe, L. A. (1983). Infant-caregiver attachment and patterns of adaptation in preschool: The roots maladaptation and competence. In M. Perlmutter (Ed.), Minnesota Symposium in Child Psychology, 16. Hillsdale, NJ: Erlbaum.

Wood, J.J., Repetti, R.L. \& Roesch, S.C. (2004). Divorce and Children's Adjustment Problems at Home and School: The Role of Depressive/Withdrawn Parenting. Child Psychiatry Hum Dev 35, 121-142. https://doi.org/10.1007/s10578-004-1881-6.

Zimbardo, P. G. (1977). Shyness: What is it and what to do about it. Reading, MA: Addison-Wesley. 